\title{
Effect of Resilient Liner on Peri-implant Structures in Early Loading Ball and Socket Implant Supported Overdentures
}

\author{
Hisham A Mously
}

\begin{abstract}
Background:The effects of fiber-reinforced acrylic base liner on peri-implant structures in early loading implant-supported overdenture are not thoroughly investigated. Hence, the aim to this study was to evaluate the effect of fiber-reinforced acrylic denture base resin liner on clinical and radiographic parameters in early loading implant supported overdentures.

Materials and methods: Fifteen edentulous male patients, aged 50-60 years were randomly (lottery method) classified into two groups: group I (controls, $n=5$ ) having 4 ball and socket implants without resilient liner, group II (study group, $n=10$ ) having ball and socket attachments with resilient liner. Group II was further divided into two subgroups: subgroup A $(n=5)$ having 2 ball and socket implants with resilient liner and subgroup B $(n=5)$ having 3 ball and socket implants with resilient liner. Implant mobility, implant survival, sulcular depth around the implant and bone height were evaluated every 3 months for 1 year. General linear models were used to test the difference in the mean crevicular depth and mean bone height (ratio) around implants in both groups during the follow-up periods. Statistical significance was determined at $\alpha=0.05$. Results: No mobility was reported and the implant survival was $100 \%$. There was an increase in the mean crevicular depth around implants in both groups at different time intervals. The increase was higher in group II $(p<0.05)$. There was a decrease in the mean bone height around the implants in both groups at different time intervals; however, this difference was not statistically significant $(p>0.05)$.

Conclusion: Furthermore, the number of implants had no significant role in the success or failure of the implant-supported overdentures.

Keywords: Implant-supported, Liners, Overdentures, Reinforced acrylic resin.

World Journal of Dentistry (2019): 10.5005/jp-journals-10015-1670
\end{abstract}

\section{INTRODUCTION}

Use of dental implants in full-mouth restorations is now a wellaccepted treatment modality with numerous modifications and implant systems. When implants are considered, treatment plans usually range from a two-implant overdenture to a completely implant-supported prosthesis. It has been reported that for implants to become osseointegrated, they must heal in the absence of functional loading for a period of 4-6 months. ${ }^{1,2}$

Until now, clinicians are trying to address patient comfort and functional requirements during the healing period. To address these needs, the concept of using transitional implants was introduced to support an interim prosthesis or used as temporary abutments for permanent overdentures. ${ }^{1-3}$

The use of transitional implants addressed patients' needs of comfort and relative function during the healing period, but rapid mobility of some transitional implants was reported and the second stage of surgery for the implant's exposure still considered time consuming and patients do not prefer adding another surgical intervention. Therefore, the concept of immediate loading of implants was introduced in the dental field. ${ }^{3}$ Regardless of the technique used, the implants and attachment occupy space that would otherwise be filled with denture resin in a conventional denture. The result is either a denture that is thinner than normal and therefore susceptible to fracture or a bulky denture that may interfere with the tongue and speech. ${ }^{4}$ To avoid these unfavorable occurrences, reinforcement to the acrylic resin overdenture while allowing for natural contours of the denture resin is performed.

A key factor for the success or failure of dental implants is the manner in which stresses are transferred to the surrounding bone. ${ }^{5,6,10}$ Resilient denture liners are increasingly used with dental
Department of Maxillofacial Prosthodontics, King Abdulaziz University, Jeddah, Kingdom of Saudi Arabia

Corresponding Author: Hisham A Mously, Department of Maxillofacial Prosthodontics, King Abdulaziz University, Jeddah, Kingdom of Saudi Arabia, Phone: +966 55738 8777, e-mail: Dr.mously@gmail.com

How to cite this article: Mously HA. Effect of Resilient Liner on Periimplant Structures in Early Loading Ball and Socket Implant Supported Overdentures. World J Dent 2019;10(5):335-339.

Source of support: Nil

Conflict of interest: None

implants for retention. ${ }^{7,8}$ When used as a method of retention for implant-retained overdentures, these liners are wear-resistant, partially obturate undercuts, absorb energy, distribute masticatory forces to the implants and edentulous ridge, and provide greater latitude of movement and comfort to the patient. ${ }^{7-9}$

The data on the effects of fiber-reinforced acrylic base liner on early loading implant-supported overdenture are still limited. Hence, this study was designed to evaluate the effect of fiber-reinforced acrylic denture base resin liner on clinical and radiographic parameters in early loading implant-supported overdentures.

\section{Materials and Methods \\ Study Design and Study Population}

A comparative clinical trial was conducted on 15 edentulous male patients, aged 50- to 60-year-old, who reported to the Department of Prosthodontics at private dental center in Jeddah city, Saudi Arabia. All of these patient were in need for maxillary and mandibular complete dentures.

(c) The Author(s). 2019 Open Access This article is distributed under the terms of the Creative Commons Attribution 4.0 International License (https://creativecommons. org/licenses/by-nc/4.0/), which permits unrestricted use, distribution, and non-commercial reproduction in any medium, provided you give appropriate credit to the original author(s) and the source, provide a link to the Creative Commons license, and indicate if changes were made. The Creative Commons Public Domain Dedication waiver (http://creativecommons.org/publicdomain/zero/1.0/) applies to the data made available in this article, unless otherwise stated. 


\section{Ethical Approval and Informed Consent}

The ethical approval was obtained from the Institutional Review Board of Magrabi Hospital (reference \#101/Z). Written informed consent was obtained from all participants after explaining to them the risks and benefits of the study in the local language. The participants were informed that they could withdraw from the study at any time.

\section{Selection of the Study Participants} Inclusion Criteria

- Old denture wearers.

- Complaint of lower denture loosening due to resorption of bone.

- No history of any systemic diseases that may influence bone resorption or complicate surgery.

- Good psychological condition to accept the work.

- Class I Angle's classification.

- Inter-arch space to accommodate for overdenture with attachment systems.

- Non-smokers.

\section{Study Groups}

Patients were randomly (lottery method) classified into two groups:

- Group I (control; $n=5$ ) -four ball and socket implants without resilient liner.

- Group II (study group; $n=10$ )—ball and socket implants with resilient liner. Group II was further divided into two subgroup:

- Subgroup A ( $n=5)$-two ball and socket implants with resilient liner.

- Subgroup B $(n=5)$-three ball and socket implants with resilient liner

\section{Study Protocol}

The complete medical and dental history of the study participants was recorded. Intra-oral examination was conducted visually and digital palpation to detect any signs of infection, inflammation, or any other abnormalities. Panoramic radiographs were used to detect any pathosis, mental nerve position, bone height, infection, remaining roots, and the position of the mandibular canal. The old denture was examined for any corrections to be used temporally after implant insertion.



Fig. 1: Transparent acrylic resin template
An acrylic surgical template was made for all study participants to determine the site of insertion of the implants in the patient's mouth (Fig. 1).

\section{Surgical Phase}

The instruments were grouped into two groups: the first one was used for the tissue punch to excise the overlying soft tissue eliminating the need for flap elevation. The second one was used for bone preparation for implant insertion, it included high torque contra angle hand piece and special kit for implant insertion. All the instruments were autoclaved.

The patients were asked to take ampicillin (500 mg) 2 days before the procedure. Each patient was given a calmpam $1.5 \mathrm{mg}$ 12 hours before surgery. The oral cavity was rinsed with $0.2 \%$ chlorohexidine before surgery. The skin surrounding the oral cavity was rubbed by $0.2 \%$ chlorohexidine solution and then by $70 \%$ alcohol.

Bilateral mandibular nerve block and mental nerve infiltration were administered to the patient. A tissue puncher was used to punch out $0.4 \mathrm{~mm}$ hole in the mucosa. The crest of the ridge was exposed; and thin ridge was flattened slowly to give broad surface for the insertion of the fixture. Acrylic template was used as a guide for the implant insertion sites. The implant site was prepared using a $2 \mathrm{~mm}$ followed by 2.5 and $3.5 \mathrm{~mm}$ diameter drills. The speed of drilling did not exceed 2,000 revolutions/minute, to a depth of $10 \mathrm{~mm}$ from the crest of the ridge. The implant was hand driven at its site and rotated until it reached its possible depth. The implant was threaded until its final depth with the implant flushed with the bone surface using a special key (Figs 2 to 4). After removing of the insertion tool from the implant, the socket was placed on its ball to act as gingival former during the healing period. The patient was instructed to take antibiotic and analgesic (penicillin, $500 \mathrm{mg}$ qid and catafast-dispersible powder $50 \mathrm{mg}$, Pfizer.) for five days after surgery. The patient was asked to have soft diet and for 7 days postoperatively.

\section{Prosthetic Phase}

Two weeks after the insertion of the implants, gingival formers were removed from the patient's mouth and replaced by the ball abutments. Construction of maxillary and mandibular complete dentures was completed following conventional methods. For group II, the lower denture was relieved in the area of the

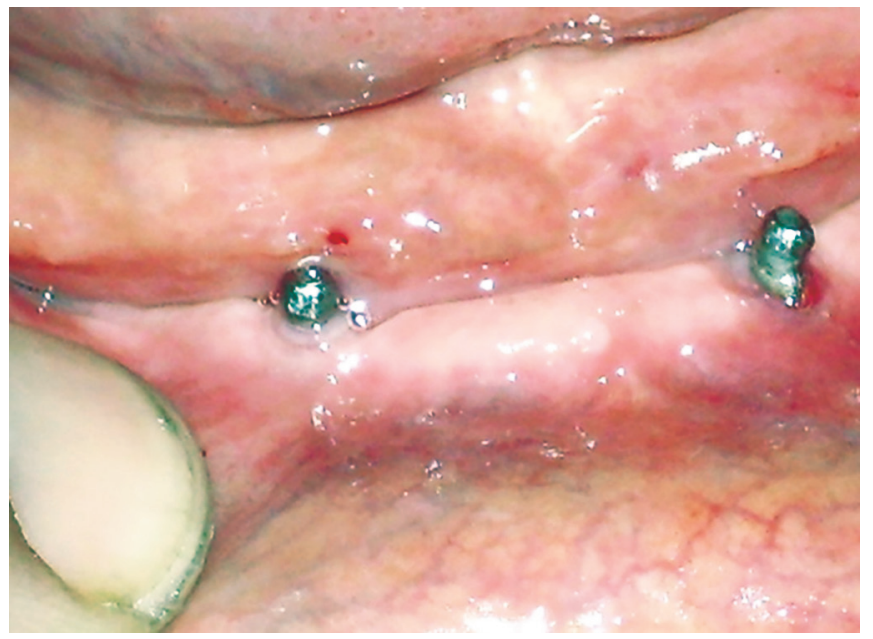

Fig. 2: Intraoral view of two ball attachments 


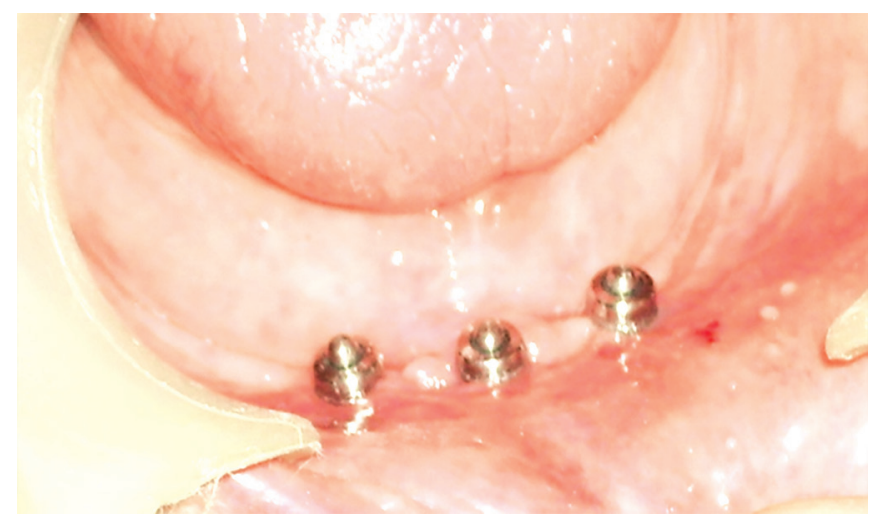

Fig. 3: Intraoral view of three implants in position

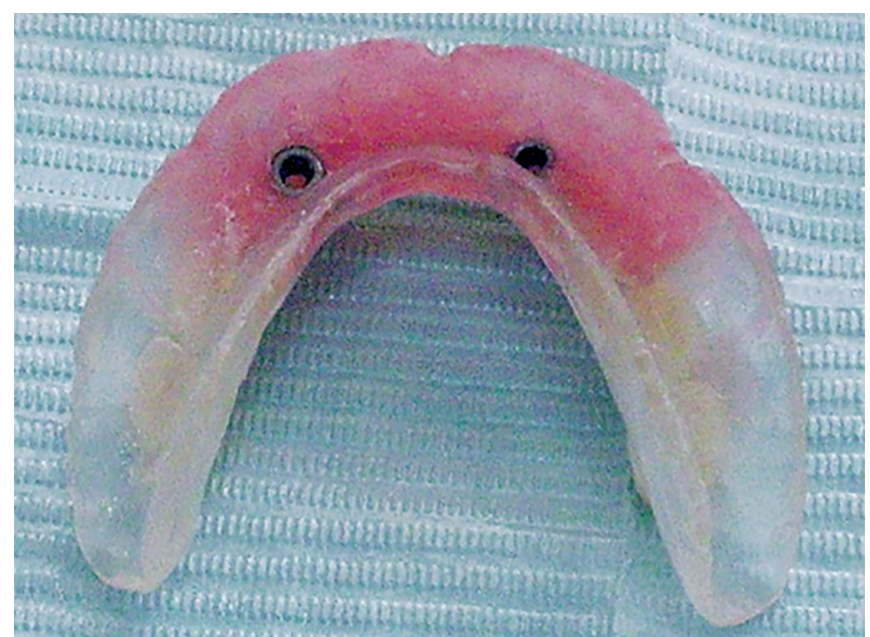

Fig. 5: Fitting surface of the denture with the female part of ball attachment

attachments. The space that was relieved was filled with self-cure acrylic. The denture was inserted in the patient's mouth until the self-cure acrylic resin was polymerized while the patient was guided to bite in centric occlusion (indirect packing of the socket). After polymerization, the lower denture was removed from the patient mouth and excess material was removed from the fitting surface of the lower denture. The excess material was removed to prevent resilient attachment of the implant to be rigid (Fig. 5). Relevant post-insertion instructions were given to patients.

\section{Follow-up}

Follow-up records were made at the time of implant insertion and every 3 months for 1 year.

\section{Evaluation Parameters \\ Clinical Evaluation}

- Implant mobility-according to small 10 mobility of the implants were tested digitally by using two-hand instruments in buccolingual and mesiodistal directions. Mobility scores used for mobility evaluation were:

- Firm with no delectable movement with light pressure.

- Movement above 0-0.5 mm.

- Movement above $0.5-2.0 \mathrm{~mm}$.

- Movement of more than $2 \mathrm{~mm}$.



Fig. 4: Intraoral view of four implants in position

- Measuring the sulcular depth: using the William's graduated periodontal probe, the sulcular depth was measured for the implant from the midbuccal-midlingual-midmesial-middistal surfaces and the mean of every implant was recorded.

Radiographic evaluation: to evaluate the level of bone around the implant mesially and distally.

Bone height changes were measured as the ratio between the changeable measure [distance between the implant crestal bone (ICB) and mandibular inferior border (MIB) at both the right and left sides] divided by fixed measures [distance between the implant bottom (IB) and MIB].

Implant bone ratio $=$ distance between ICB and MIB/distance between IB and MIB.

Every implant was expressed in the data analysis by one reading representing the mean of the mesial and distal bone level. The success or failure rate was considered for the number of implants.

\section{Statistical Analysis}

The data were analyzed using SPSS V.14.0 software (IBM Statistics, SPSS, Chicago, USA). General linear models were used to test the difference in the mean crevicular depth and mean bone height (ratio) around implants in both groups through the follow-up periods. Statistical significance was determined at $\alpha=0.05$.

\section{Results}

Forty-five screw osseointegrated implants were installed in completely edentulous lower jaw opposing completely edentulous maxillary ridges for 15 patients and were followed up clinically and radiographically every 3 months for a year. The implants were early loaded by mandibular overdentures. Patients were classified into two equal groups. Implants of group I were the reinforced overdenture retained by ball and socket attachments without resilient liner while that of group II were the reinforced overdenture retained by ball and socket attachments using resilient liner.

\section{Clinical Findings \\ Implant Mobility \\ There was no sign of mobility of the implants.}




\section{Implants Survival Rate}

All implants were functioning all over this 1-year study, so the survival rate of the implants used was $100 \%$ from the clinical perspective.

\section{Crevicular Depth Changes}

It was found that there was an increase in the mean crevicular depth around implants of both groups at different time intervals. The increase was higher in group II (Table 1). The statistical analysis showed that the differences between groups were significant where $p=0.028^{*}(F=15.861$ at $p<0.05)$. It also showed that the differences between the time intervals were highly significant where $p=0.014^{* *}$ $(F=23.500$ at $p<0.05)$ (Table 2).

\section{Peri-implant Bone Changes}

It was observed that there was a decrease in the mean bone height around the implants of both groups at different time intervals. The decrease was higher in group II (Table 3). The statistical analysis showed that the differences between the groups were not significant, $p=0.235(F=2.197)$ and it also showed that the differences between the time intervals were highly significant where $p=0.02(F=17.307)$ (Table 4).

Table 1: Mean crevicular depth $(\mathrm{mm})$ around implants in both groups through the follow-up periods

\begin{tabular}{lllll}
\hline & \multicolumn{5}{c}{ Time/month } \\
\cline { 2 - 5 } Group & 0 & 3 & 6 & 12 \\
\hline I & 1.00 & 1.13 & 1.25 & 1.75 \\
II & 1.25 & 1.38 & 1.63 & 1.83 \\
\hline
\end{tabular}

Table 2: Comparison of mean crevicular depth $(\mathrm{mm})$ between the two groups and time intervals

\begin{tabular}{llllll}
\hline Source & $\begin{array}{l}\text { Type ll sum of } \\
\text { squares }\end{array}$ & Df & Mean square & $F$ & Sig. \\
\hline Model & $16.378^{\mathrm{a}}$ & 5 & 3.276 & 460.551 & 0.000 \\
Group & 0.113 & 1 & 0.113 & 15.861 & 0.028 \\
Time & 0.501 & 3 & 0.167 & 23.500 & 0.014 \\
Error & $2.134 \times 10^{-2}$ & 3 & $7.112 \times 10^{-3}$ & & \\
Total & 16.400 & 8 & & & \\
\hline
\end{tabular}

$\mathrm{Df}=$ degree of freedom. ${ }^{\mathrm{a}} R$ squared $=0.999($ adjusted $R$ squared $=0.997)$

Table 3: Mean bone height (ratio) around implants in both groups through the follow-up periods

\begin{tabular}{lllll}
\hline & \multicolumn{4}{c}{ Time/month } \\
\cline { 2 - 5 } Group & 0 & 3 & 6 & 12 \\
\hline I & 1.541 & 1.508 & 1.480 & 1.446 \\
II & 1.540 & 1.504 & 1.466 & 1.341 \\
\hline
\end{tabular}

\section{Discussion}

The present study was conducted to evaluate the effect of resilient liner on peri-implant structures with early loading ball and socket implant-supported overdentures among 15 completely edentulous male patients. It was observed that there was no statistically significant difference in the clinical and radiographic parameters among the two study groups.

All patients included in the study were clinically free from any systemic and blood diseases to avoid the risk of complications from bone resorption that may lead to the failure of implants and the risk of bleeding during or after surgery. ${ }^{11,12}$ The study participants belonged to the same sex and age-group to minimize confounding variables during surgery and prosthetic phase. Female individuals were excluded from the study because there is a higher risk of bone resorption due to hormonal changes. ${ }^{13}$ Smokers were excluded from the study because smoking has been associated with increased incidence of peri-implantitis, deep mucosal pockets around implants, and increased gingival index. ${ }^{14}$

All the surgical instruments were sterilized by the autoclave, with the titanium instruments were isolated from stainlesssteel instruments to avoid metal contamination of the titanium instruments that may affect osseointegration. ${ }^{15}$

The long-term success of implants depends on the patient's ability and willingness to control etiologic factors responsible for the onset and progression of peri-implantitis. ${ }^{16}$ Therefore, psychologic evaluation of the patients was conducted before the procedure. Also, proper post-insertion instructions were given to patients.

Digital image processing was used to measure the peri-implant bone changes as this method is reliable and precise. Although the bone changes were evaluated digitally, these changes were also measured in ratios to eliminate any possibility of magnification error in panoramic X-rays. ${ }^{17}$

Implant-supported overdenture offers many advantages compared with teeth overdenture or conventional dentures. These include improved retention, stability, and stable occlusion, simplicity, irretrievability, ease of follow-up, and avoidance of pre-prosthetic surgery. Moreover, implants reduce further bone resorption and minimize clinical complications. ${ }^{18-21}$ The most compelling advantage of implant-supported prosthesis is the long-term success rate $(95.5 \%$ after 20 years for implants vs $80 \%$ for abutment overdenture). ${ }^{18,22}$

Furthermore, a new accepted standard of care procedure for patients with complete mandibular edentulism was established in 2002 that offers two-implant overdentures placed interforaminally, with the possibility of immediate loading, as the primary treatment of care. ${ }^{18}$ However, the two-implant overdenture should not be considered the gold standard, but the minimum standard of implant therapy offered to edentulous patients. Also, the treatment plan should account for function, patient satisfaction, cost, clinical time, and patient preference. ${ }^{18,23}$

Table 4: Comparison between the two groups and time intervals as regard the mean bone height (ratio)

\begin{tabular}{llllll}
\hline Source & Type ll sum of squares & Df & Mean square & S & \\
\hline Model & $17.647^{\mathrm{a}}$ & 5 & 3.529 & $11,330-196$ & 0.000 \\
Group & $6.845 \times 10^{-4}$ & 1 & $6.845 \times 10^{-4}$ & 2.197 & 0.235 \\
Time & $1.617 \times 10^{-2}$ & 3 & $5.391 \times 10^{-3}$ & 17.307 & 0.021 \\
Error & $9.345 \times 10^{-4}$ & 3 & $3.115 \times 10^{-4}$ & & \\
Total & 17.648 & 5 & & & \\
\hline
\end{tabular}

${ }^{\mathrm{a}} R$ squared $=1.000$ (adjusted $R$ squared $=1.000$ ) 
In addition, for implant-supported overdentures, it has been established that the implants and prostheses success rate or patient satisfaction is independent of the number of implants or abutment type. The number of implants used to support the overdenture (two, four, and six implants) does not influence its masticatory function. ${ }^{24,25}$ In the present study, two or three and four implants were used in the study and the control group, respectively.

In general, implant-supported overdenture attachments can be classified as studs, magnets, and bars. ${ }^{18}$ Ball attachments are considered to be the simplest and reliable attachments for clinical application implant-supported overdentures. They are costeffective, less technique sensitive, and easier to maintain. ${ }^{26}$ The ball and socket attachment was used in the present study for its simplicity and ease of use.

In the present study, a statistically significant difference was observed between the overdentures with liners and without liner probing depth with the probing depth being higher in the study group with resilient liner. This result is in contrast to that of Elsyad and Shoukouki results. ${ }^{7}$ However, this difference might be due to the type of liners used in both studies. The latter used autopolymerized addition silicone-resilient liner, whereas in the present study selfcure acrylic resin was used.

It was observed that the total increase in crevicular depth in group I was higher than that in group II, while the overall decrease in mean bone height ratio in group II was higher than that in group I. This might indicate that the pockets around implants of group II were true pockets, while that of group I were pseudopockets due to mucosal inflammation.

The placement of four implants for overdenture is indicated in patients with poor posterior anatomy and soft tissue abrasion that lack retention and stability. Hence, the use of four implants is suggested to obtain greater stability and more limited posterior movement, which results in a decrease in the offset load that is transmitted to the implant.

\section{Conclusion}

Based on the results of this study, it could be concluded that

- There was no difference in the clinical and radiographic parameters between the study and the control groups;

- The number of implants plays no significant role in the success or failure of the implant-supported overdentures.

\section{References}

1. Kopp CD. Overdentures and osseointegration. Case studies in treatment planning. Dent Clin North Am 1990;34(4):729-739.

2. Brånemark PI. Osseointegration and its experimental background. J Prosthet Dent 1983;50(3):399-410. DOI: 10.1016/s00223913(83)80101-2.

3. Simon $\mathrm{H}$. Use of transitional implants to support a surgical guide: enhancing the accuracy of implant placement. J Prosthet Dent 2002;87(2):229-232. DOI: 10.1067/mpr.2002.121824.

4. Duncan JP, Freilich MA, Latvis CJ. Fiber-reinforced composite framework for implant-supported overdentures. J Prosthet Dent 2000;84(2):200-204. DOI: 10.1067/mpr.2000.108025.

5. Freilich MA, Duncan JP, Alarcon EK, et al. The design and fabrication of fiber-reinforced implant prostheses. J Prosthet Dent 2002;88(4): 449-454. DOI: 10.1067/mpr.2002.128173.
6. Van Ripen FM, Vander Bill A, Cane MS, et al. Masticatory function with implant-supported overdentures. J Dent Res 2004;83(9):708-711. DOI: 10.1177/154405910408300910.

7. Elsyad MA, Shoukouki AH. Resilient liner vs. clip attachment effect on peri-implant tissues of bar-implant retained mandibular overdenture: a 1-year clinical and radiographical study. Clin Oral Implants Res 2010;21(5):473-480. DOI: 10.1111/j.1600-0501.2009.01879.x.

8. Kiat-Amnuay S, Khan Z, Gettleman L. Overdenture retention of four resilient liners over an implant bar. J Prosthet Dent 1999;81(5): 568-573. DOI: 10.1016/S0022-3913(99)70211-8.

9. Adrian ED, Krantz WA, Ivanhoe JR. The use of processed silicone to retain the implant-supported tissue-borne overdenture. J Prosthet Dent 1992;67(2):219-222. DOI: 10.1016/0022-3913(92)90457-I.

10. Small IA. The mandibular staple bone plate. Its use and advantages in reconstructive surgery. Dent Clin North Am 1986;30(2):175-187.

11. Halton JE, Heath MR, Chaij Y, et al. Factors related to success and failure rates at 3-year follow up in multicenter study of overdentures supported by Branemark implants. Int J Oral Maxillofac Implants 1992;10(1):33-47.

12. Smith RA, Berger R, Dodson TB. Risk factors associated with dental implants in healthy and medically compromised patients. Int J Oral Maxillofac Implants 1992;7(3):367-372.

13. Jacobs R, Schotte A, Van Steenberghe D, et al. Posterior jaw bone resorption in osseointegrated implant-supported overdentures. Clin Oral Implants Res 1992;3(2):63-70. DOI: 10.1034/j.16000501.1992.030203.x.

14. Haas R, Haimböck W, Mailath G, et al. The relationship of smoking on peri-implant tissue: a retrospective study. J Prosthet Dent 1996;76(6):592-596. DOI: 10.1016/s0022-3913(96)90435-7.

15. Roberts E, Smith RK, Ziberinan Y. Osseous adaptation to continous loading of rigid endosseous implants. Am J Orthrd 1984;86(2):95-111. DOI: 10.1016/0002-9416(84)90301-4.

16. Shue L, Miron RJ, Yufeng Z. Review of implant support for the distal extension removable partial dentures. JSM Dent Surg 2016;1(1):1007.

17. Rungcharassaeng K, Lozada JL, Kan JY, et al. Peri-implant tissue response of immediately loaded, threaded, HA-coated implants: 1-year results. J Prosthet Dent 2002;87(2):173-181. DOI: 10.1067/mpr.2002.121111.

18. Nissan J. Implant-supported overdentures: benefits and risks. In: Oral Rehabilitation for Compromised and Elderly Patients. Cham: Springer; 2019. pp. 183-191.

19. Awad MA, Lund JP, Dufresne E, et al. Comparing the efficacy of mandibular implantretained overdentures and conventional dentures among middle-aged edentulous patients: satisfaction and functional assessment. Int J Prosthodont 2003;16(2):117-122.

20. Bergendal T, Engquist B. Implant-supported overdentures: a longitudinal prospective study. Int J Oral Maxillofac Implants 1998;13(2):253-262.

21. Burns DR. Mandibular implant overdenture treatment: consensus and controversy. J Prosthodont 2000;9(1):37-46. DOI: 10.1111/j.1532849x.2000.00037.x.

22. Ettinger RL, Qian F. Abutment tooth loss in patients with overdentures. J Am Dent Assoc 2004;135(6):739-746. quiz 795-796. DOI: 10.14219/ jada.archive.2004.0300.

23. Thomason JM, Feine J, Exley C, et al. Mandibular two implantsupported overdentures as the first choice standard of care for edentulous patients-the York Consensus Statement. Br Dent J 2009;207(4):185. DOI: 10.1038/sj.bdj.2009.728.

24. Fueki K, Kimoto K, Ogawa T, et al. Effect of implant supported or retained dentures on masticatory performance: a systematic review. JProsthet Dent 2007;98(6):470-477.DOI: 10.1016/S0022-3913(07)60147-4.

25. Bakke M, Holm B, Gotfredsen K, et al. Masticatory function and patient satisfaction with implant-supported mandibular overdentures: a prospective 5-year study. Int J Prosthodont 2002;15(6):575-581.

26. Chung KH, Chung CY, Cagna DR, et al. Retention characteristics of attachment systems for implant overdentures. J Prosthodont 2004;13(4):221-226. DOI: 10.1111/j.1532-849X.2004.04042.x. 